Influence of Chromium and

Molybdenum on the Corrosion of Nickel Based Alloys

J. R. Hayes, J. Gray, A. W. Szmodis, C. A. Orme

August 11, 2005

Journal of the Electrochemical society 
This document was prepared as an account of work sponsored by an agency of the United States Government. Neither the United States Government nor the University of California nor any of their employees, makes any warranty, express or implied, or assumes any legal liability or responsibility for the accuracy, completeness, or usefulness of any information, apparatus, product, or process disclosed, or represents that its use would not infringe privately owned rights. Reference herein to any specific commercial product, process, or service by trade name, trademark, manufacturer, or otherwise, does not necessarily constitute or imply its endorsement, recommendation, or favoring by the United States Government or the University of California. The views and opinions of authors expressed herein do not necessarily state or reflect those of the United States Government or the University of California, and shall not be used for advertising or product endorsement purposes. 


\title{
Influence of Chromium and Molybdenum on the Corrosion of Nickel Based Alloys
}

\author{
J.R. Hayes ${ }^{1}$, J.J. Gray, A.W. Szmodis, C.A. Orme \\ Lawrence Livermore National Laboratory, 7000 East Ave., Livermore, CA 94550, \\ USA \\ ${ }^{1}$ Corresponding Author: JRHayes@llnl.gov
}

\begin{abstract}
:
The addition of chromium and molybdenum to nickel creates alloys with exceptional corrosion resistance in a diverse range of environments. This study examines the complementary roles of $\mathrm{Cr}$ and $\mathrm{Mo}$ in $\mathrm{Ni}$ alloy passivation. Four nickel alloys with varying amounts of chromium and molybdenum were studied in 1 molar salt solutions over a broad $\mathrm{pH}$ range. The passive corrosion and breakdown behavior of the alloys suggests that chromium is the primary element influencing general corrosion resistance. The breakdown potential was nearly independent of molybdenum content, while the repassivation potential is strongly dependant on the molybdenum content. This indicates that chromium plays a strong role in maintaining the passivity of the alloy, while molybdenum acts to stabilize the passive film after a localized breakdown event.
\end{abstract}

Keywords: nickel alloy; cyclic voltammetry; potentiostatic; repassivation

\section{Introduction:}

Nickel based alloys are among the most corrosion resistant alloys in a broad range of environments. The amount of chromium and molybdenum present in the alloy has a significant effect on the corrosion properties of the metal. This study examines the influence of chromium and molybdenum on four nickel based alloys (Table 1), including Alloy 22 (UNS06022), in various salt brines. Alloy 22 is a highly corrosion resistant nickel based alloy which has a range of uses including dental implants and in industrial settings where highly corrosive environments are encountered. In general use, Alloy 22 
often comes in contact with concentrated brines at elevated temperatures. Alloy 22 was used as a standard alloy, and two ternary alloys were chosen based on the alloy 22 composition, but with varying amounts of the primary passivating components ( $\mathrm{Cr}$ and Mo). The ternary compositions were Ni-11Cr-7Mo, and Ni-11Cr-13Mo. A binary alloy with 20 wt. \% chromium was also examined.

The corrosion resistance of several Ni-Cr-Mo alloys have been discussed in detail [1]. In brief summary, Alloys C, C-276, C-4 and Inconel alloy 625 have been tested for corrosion resistance in acidic solutions including $\mathrm{HCl}, \mathrm{H}_{2} \mathrm{SO}_{4}, \mathrm{HNO}_{3}, \mathrm{HF}$ and $\mathrm{H}_{3} \mathrm{PO}_{4}$. The alloys with higher molybdenum content usually show the best resistance to reducing environments such as $\mathrm{H}_{2} \mathrm{SO}_{4}$ and $\mathrm{HCl}$ and pitting attacks from $\mathrm{Cl}$ containing solutions, while the alloys with higher chromium content usually have the best resistance to strongly oxidizing solutions such as nitric acid.

Hodge and Wilde, using anodic polarization techniques in $0.5 \mathrm{M} \mathrm{H}_{2} \mathrm{SO}_{4}+1 \mathrm{M}$ $\mathrm{NaCl}$ at $25{ }^{\circ} \mathrm{C}$, found that $\mathrm{Ni}-\mathrm{Cr}$ alloys containing more than $10 \%$ chromium develop passivity [2]. A similar effect of the addition of chromium to Ni was shown by Piron $e t$ al. with a potentiostatic anodic polarization study of Ni 200 and Inconel 600 in $0.5 \mathrm{M}$ $\mathrm{H}_{2} \mathrm{SO}_{4}$ solutions at $24^{\circ} \mathrm{C}$ to which was added sodium chloride in various amounts from 0 to 3.5 wt. \% [3]. A quantitative measure of the effect of chloride ions on the passivity of those two materials in $0.5 \mathrm{M} \mathrm{H}_{2} \mathrm{SO}_{4}$ was achieved by maintaining the potential of each electrode within the passive region (+600 mV vs. SHE in the case of Inconel and +500 $\mathrm{mV}$ vs. SHE in the case of $\mathrm{Ni}$ ). Subsequently, the concentration of chloride ions was increased by the addition of increments of a concentrated sodium chloride solution. At each concentration, the steady state passive current density was measured. The results showed that, for each material, the breakdown of passivity occurred at a critical $\mathrm{NaCl}$ concentration.

The addition of Mo to Ni based alloys has been shown to decrease corrosion rates[4-6]. Several plausible explanations for the mechanisms responsible for increased corrosion resistance with increased Mo content have been developed. Among these, it has been proposed that a primary function of Mo is to retard the propagation of localized corrosion once the passive film breakdown has occurred. It has been postulated that Mo 
preferentially locates at local defects on the surface, which otherwise would act as dissolution sites [4,5].

The influence of chromium and molybdenum on the passive behavior and localized breakdown of both stainless steels and nickel based alloys is a subject under active debate. These two alloying elements both act together to change the properties of both the passive film as well as the solutions that form due to the metal dissolution, which can lead to pit and crevice environments. In this paper, the electrochemical behavior of Alloy 22 in various brine conditions is examined in detail, and compared with simplified binary and ternary nickel based alloys to elucidate the role of $\mathrm{Cr}$ and $\mathrm{Mo}$ in the passive behavior of Alloy 22.

\section{Experimental Conditions:}

Four alloys were tested: Ni-20Cr, Ni-11Cr-7Mo, Ni-11Cr-13Mo, and Alloy 22 (Ni22Cr-13Mo-3W-3Fe). The weight percent composition, density, and equivalent weights of these alloys is detailed in Table 1. The densities of the alloys were calculated from a weighted average of the densities of their constituent elements. The equivalent weights in $\mathrm{g} /$ mol-equivalent for all alloys were calculated from a weighted average of the most common ionization states of their constituent elements (ASTM G 102 [7]). All of the specimens were milled into discs $5 / 8$ " in diameter and $1 / 8$ " thick, and polished to 0.02

$\mu \mathrm{m}$ colloidal silica. An ID number was milled into the back of the disc. The electrochemical tests were performed in a round bottom flask placed in a hot silicone oil bath. The bath was held at a temperature such that the electrolyte solution maintained a temperature of $90^{\circ} \mathrm{C}$. $900 \mathrm{ml}$ of electrolyte solution used for each experiment. A nitrogen bubbler flowing 99.999\% pure $\mathrm{N}_{2}$ gas deaerated the solution for the duration of the experiments. A condenser tube connected to a chilled water line held at $15^{\circ} \mathrm{C}$ prevented evaporation of the electrolyte. A water cooled $\left(15{ }^{\circ} \mathrm{C}\right)$ Luggin probe salt bridge containing the test electrolyte connected a saturated $\mathrm{Ag} / \mathrm{AgCl}$ (SSC) reference electrode to the electrolyte $\left(0.209 \mathrm{~V}\right.$ vs. SHE at $\left.15^{\circ} \mathrm{C}\right)$. The reference electrodes were calibrated with respect to quinhydrone with a variance of less than $\pm 10 \mathrm{mV}$. A platinum counter electrode consisting of a platinum wire spot-welded to a 2 x $7 \mathrm{~cm}$ platinum foil flag was placed approximately 3 centimeters away from the specimen surface. The 
specimens were held in a vertical position to prevent corrosion products from settling on the surface, and to minimize the diffusion depleted region in front of the specimen through convection of the electrolyte. The electrolyte was not stirred, but was agitated by nitrogen bubbling. The samples were held using a Teflon washer such that only the polished face of the specimen was exposed, with an approximate area of $0.7 \mathrm{~cm}^{2}$. The Luggin probe tip was placed approximately $5 \mathrm{~mm}$ from the surface of the specimen.

It should be noted that because the reference electrode was operated at $15{ }^{\circ} \mathrm{C}$, and the working electrode at $90{ }^{\circ} \mathrm{C}$, two corrections must be made when using these data with standard potential tables, which are measured at $25{ }^{\circ} \mathrm{C}$. To compare with standard reference potentials, the working electrode, reference electrode, and reaction of interest must all be adjusted to the same temperature. To correct the reference electrode due to the liquid junction thermal gradient, the equation $\mathrm{E}=\mathrm{E}^{0}-1.01\left(\mathrm{~T}^{0}-\mathrm{T}\right)$ is used, where $\mathrm{E}^{0}$ is the potential of saturated $\mathrm{Ag} / \mathrm{AgCl}$ at $15{ }^{\circ} \mathrm{C}(0.209 \mathrm{~V}$ vs. SHE$), \mathrm{T}^{0}$ is $15{ }^{\circ} \mathrm{C}$, and $\mathrm{T}$ is the temperature of the working electrode $\left(90{ }^{\circ} \mathrm{C}\right)$. This correction is $-75 \mathrm{mV}$. Secondly, redox reactions are normally given in tables referenced to $25{ }^{\circ} \mathrm{C}$. Therefore this value must be corrected to $90{ }^{\circ} \mathrm{C}$ using the Nernst equation. For example the $\mathrm{H}_{2} \mathrm{O} \rightarrow \mathrm{O}_{2}$ redox potential at $90^{\circ} \mathrm{C}$ and $\mathrm{pH} 3,8$, and 11 is $0.814,0.453$, and $0.237 \mathrm{~V}$ respectively.

A series of electrochemical tests were performed on each sample. Before the specimens were immersed, the solution was deaerated with $\mathrm{N}_{2}$ for $1 \mathrm{hr}$., and the temperature and $\mathrm{pH}$ values were recorded. The specimen was then inserted and the open circuit potential or corrosion potential $\left(\mathrm{E}_{\text {corr }}\right.$ ), was monitored, typically for 24 hours. All electrochemical measurements were performed using a commercial potentiostat / galvanostat / zero resistance ammeter. After the corrosion potential was measured, one or several of the following tests were performed. Polarization resistance scans were performed according to ASTM G 59 [7] directly after the corrosion potential monitoring. These scans were repeated 3 times to get an average polarization resistance. Current was recorded as the potential was scanned from $20 \mathrm{mV}$ below, to $20 \mathrm{mV}$ above the instantaneous $\mathrm{E}_{\text {corr, }}$ at a rate of $0.1667 \mathrm{mV} / \mathrm{sec}$. The slope of this line, $\Delta V / \Delta I$, yields $R_{P}$, the polarization resistance. 
After the polarization resistance scans, potentiodynamic polarization scans or potentiostatic polarization experiments at selected potentials were performed (ASTM G 61 [7]). The potentiodynamic polarization scans were performed to examine the passive and breakdown behavior of the alloy. They were typically run from $200 \mathrm{mV}$ below the instantaneous $\mathrm{E}_{\text {corr }}$ up to $5 \mathrm{~mA} / \mathrm{cm}^{2}$ or $2000 \mathrm{mV}$ above $\mathrm{Ag} / \mathrm{AgCl}$ (whichever came first) at a scan rate of $0.1667 \mathrm{mV} / \mathrm{sec}$. The voltage was then scanned back to the original $\mathrm{E}_{\text {corr }}$ value. In the figures in this paper, the data was truncated after repassivation occurred to clarify the plots. Potentiostatic tests were done by stepping the potential instantaneously to a value of interest, and holding it there for 60,000 seconds.

The anodic behavior of the four alloys was examined in several solutions. The tests were performed in $1 \mathrm{M} \mathrm{NaCl}$ with pH's adjusted to 3 , 8, or 11 with acids, bases, and buffers. The solution compositions and nominal $\mathrm{pH}$ values are shown in Table 2, with an identifying moniker which will be referred to in the text. The buffers phthalate and borate were used to buffer the solutions at $\mathrm{pH} 3$ and 8 respectively.

\section{$\underline{\text { Results: }}$}

The results from the electrochemical experiments will be presented in three sections: potentiodynamic polarization curves, corrosion rates calculated from polarization resistance, and corrosion rates calculated from the final current reached during potentiostatic polarization. Potentiodynamic polarizations provide a metric for comparing the behavior of various alloys in a given electrolyte, as well as indicate the alloys susceptibility to localized breakdown and corrosion. In addition, Tafel constants can be extracted from the activation region of the potentiodynamic curve near the open circuit potential. These Tafel values can then be used with the polarization resistance data to estimate the corrosion rate of the alloy.

\section{Potentiodynamic Polarization:}

All four alloys were tested in $1 \mathrm{M} \mathrm{NaCl}$ solutions at nominal $\mathrm{pH}$ values of 3, 8, and 11. Figures 1-3 show potentiodynamic polarization scans of the 4 metals grouped by $\mathrm{pH}$. The potentiodynamic scans were truncated in the reverse scan direction after repassivation occurred in order to clarify the figure. Multiple scans were performed, and 
representative data sets are presented. Figure 1 shows the cyclic behavior of the four alloys in $1 \mathrm{M} \mathrm{NaCl}$ with a $\mathrm{pH}$ of $3.09 \pm 0.37$. All of the alloys show a distinct passive region at a current density of $10^{-6} \mathrm{~A} / \mathrm{cm}^{2}$. The $\mathrm{E}_{\text {corr }}$ of the Mo containing alloys are within $100 \mathrm{mV}$ of $-350 \mathrm{mV}$ SSC. Ni-20Cr was slightly higher at $-100 \mathrm{mV}$. The largest difference can be seen in the transpassive breakdown and repassivation behaviors. Ni$20 \mathrm{Cr}$ (Fig. 1A), with no Mo, had a sudden increase in current at $400 \mathrm{mV}$, and once complete breakdown occurred at $680 \mathrm{mV}$, did not repassivate during the reverse scan. Ni-11Cr-7Mo (Fig. 1B), which has 7\% Mo, showed evidence of pitting at $350 \mathrm{mV}$, finally breaking down completely at $590 \mathrm{mV}$, and did not repassivate until near its original $\mathrm{E}_{\text {corr }}$ Both alloys $\mathrm{Ni}-20 \mathrm{Cr}$ and $\mathrm{Ni}-11 \mathrm{Cr}-7 \mathrm{Mo}$ showed severe pitting. Two specimens of $\mathrm{Ni}-11 \mathrm{Cr}-13 \mathrm{Mo}$, with $13 \% \mathrm{Mo}$, were tested, one displaying a more active behavior than the other (Fig. 1C). Both specimens had a distinct passive region $900 \mathrm{mV}$ wide, and broke down near $650 \mathrm{mV}$. One specimen had a small hysteresis, and repassivated near the breakdown potential at $550 \mathrm{mV}$ (shown as a solid line). This specimen showed no evidence of pitting. The second specimen, however, had a large hysteresis, and did not repassivate until $-125 \mathrm{mV}$ (shown as a dashed line). Large pits formed on the surface. Alloy 22, also with $13 \%$ Mo, but with more chromium than Ni11Cr-13Mo (Fig. 1D) had a large passive region, spanning $1030 \mathrm{mV}$ before breaking down, and had no hysteresis when repassivating. No evidence of pitting was seen on the surface.

Figure 2 shows the behavior of the 4 alloys tested at $\mathrm{pH} 7.78 \pm 0.22$. $\mathrm{Ni}-20 \mathrm{Cr}$ (Fig. 2A) had a passive region of $550 \mathrm{mV}$, breaking down near $400 \mathrm{mV}$. Once the alloy broke down, it did not repassivate. Large pits formed in the surface. Ni-11Cr-7Mo (Fig. 2B) broke down at a lower voltage of $85 \mathrm{mV}$. It had a large hysteresis before repassivation at $-350 \mathrm{mV}$. Large pits formed at the surface. Ni-11Cr-13Mo (Fig. 2C) demonstrated the same dual behavior between two samples in $\mathrm{pH} 8$ as it did in $\mathrm{pH} 3$. Two specimens were tested, one displaying a more active behavior than the other. The active specimen broke down at $675 \mathrm{mV}$, had a large hysteresis loop, and did not repassivate until -200 $\mathrm{mV}$ (shown as a dashed line). Large pits formed on the surface. The second specimen (shown as a solid line) displayed an anodic peak at $435 \mathrm{mV}$, after which the current dropped to near its passive current rate, before breaking down 
completely. The potentiodynamic curve displays a large hysteresis and the sample formed large pits in the surface. Alloy 22 (Fig. 2D) also had the anodic peak at $400 \mathrm{mV}$, but did not completely breakdown until $675 \mathrm{mV}$. It has a small hysteresis before repassivating at $445 \mathrm{mV}$. No pits were observed on the surface.

Figure 3 shows the potentiodynamic curves of the four alloys in $1 \mathrm{M} \mathrm{NaCl}$ at $\mathrm{pH}$ $10.96 \pm 0.05$. In the basic solution, all of the alloys demonstrated an extensive passive region, and all experienced transpassive breakdown down near $500 \mathrm{mV}$, which is attributed to oxygen evolution at the working electrode. All of the Mo containing alloys had very little hysteresis, indicating the breakdown of the electrolyte had very little effect on the sample. Ni-11Cr-7Mo (Fig. 3B) had a passive region spanning $1200 \mathrm{mV}$, larger than both Ni-11Cr-13Mo (1100 mV, Fig. 3C) and Alloy 22 (900 mV, Fig. 3D). The smaller passive regions were caused by an increase in the open circuit potential, since the transpassive breakdown potential is due to breakdown of the electrolyte, and so is invariant. By contrast, the alloy without Mo, Ni-20Cr (Fig. 3A) had a very large hysteresis, but $\mathrm{pH} 11$ was the only solution where $\mathrm{Ni}$-20Cr repassivated, which occurred at $-370 \mathrm{mV}$ (Fig. 3A). Large pits were observed on the surface of Ni-20Cr, none of the other alloys had pitting.

It should be noted that XPS revealed the existence of a layer of silica on the surface of all samples tested in $\mathrm{pH} 11$ solutions. This is attributed to silica dissolving from the glassware due to the caustic solution and redepositing on the surface of the samples. This layer may influence the electrochemical behavior, however, since the testing conditions were the same for all alloys, the relative behaviors can still be compared.

Figure 4 compares the breakdown and repassivation behavior of the alloys in the different solutions. Open circles represent the breakdown potentials and open triangles represent repassivation potentials. These data were derived from cyclic polarization scans (Figures 1-3), two of which were measured for each alloy in each solution. The vertical tie bars show the potential difference between transpassive breakdown and repassivation, and aid in comparing the behaviors of the alloys. The alloys have strong passive regions spanning over $800 \mathrm{mV}$ at $\mathrm{pH} 3$ and 11. At $\mathrm{pH} 8$, the alloys have larger active regions, on the order of $400 \mathrm{mV}$. In the acidic solution, breakdown of all 4 alloys 
occurs near the same potential, around $650 \mathrm{mV}$. Also plotted in this figure are horizontal lines indicating the oxygen evolution potentials under the test conditions. The dashed line is a calculated redox potential for oxygen at the indicated $\mathrm{pH}$ value at $90{ }^{\circ} \mathrm{C}$ with an estimated oxygen partial pressure of $10^{-6}$ atm. As can be seen, these lines are well below the breakdown potential measured for most of the alloys. However, oxygen evolution has a considerable overpotential, as can be seen by the dashed line, which is the actual oxygen evolution potential measured under test conditions on a platinum working electrode. The measured value is between 270 and $380 \mathrm{mV}$ above the calculated value. Optical microscopy of the samples after potentiodynamic testing indicate that at $\mathrm{pH} 3$ and 8, all of the samples show evidence of either pitting, crevicing, or general alloy dissolution. At $\mathrm{pH}$ 11, only the Ni-20Cr sample showed evidence of pitting, the other three alloys were not attacked. This indicates that under the $\mathrm{pH} 11$ test conditions, transpassive breakdown of $\mathrm{Ni}-11 \mathrm{Cr}-7 \mathrm{Mo}$, Ni-11Cr-13Mo, and Alloy 22 is due to breakdown of the electrolyte, and not the alloys. Taken together, Figure 4 illustrates that repassivation after breakdown is strongly dependent on molybdenum content. The repassivation potential increases as molybdenum increases.

\section{Polarization Resistance:}

Polarization resistance measurements were made on all specimens tested in the 1 $\mathrm{M} \mathrm{NaCl}$ solutions. In order to determine a corrosion rate from these tests, the Tafel constants for the alloys in each specific solution need to be determined. Tafel constants can be extracted from potentiodynamic polarization curves near the open circuit potential in the activation polarization range [8,9]. In this range, the activation current/potential relationship for anodic polarization (positive to the open circuit potential) is given by:

$$
\eta_{a}=\beta_{a} \log \frac{i_{a}}{i_{0}}
$$

Where $\eta_{a}$ is the anodic overpotential, $\beta_{a}$ is the anodic Tafel constant, $i_{a}$ is the anodic current density, and $i_{0}$ is the exchange current density of the reaction at equilibrium (zero overpotential). Similarly, the cathodic reaction can be written as: 


$$
\eta_{c}=\beta_{c} \log \frac{i_{c}}{i_{0}}
$$

Where $\eta_{c}$ is the cathodic overpotential (negative), $\beta_{c}$ is the cathodic Tafel constant, and $i_{c}$ is the cathodic current density. The slope of the linear activation polarization portion of the potentiodynamic polarization curves plotted as potential vs. log current density has a slope of $\beta_{a}$ (in the anodic region) and $\beta_{c}$ (in the cathodic region). Thus, the Tafel constants can be determined experimentally for all alloy/solution combinations. Table 3 contains the Tafel constants measured for the alloy/solution combinations. When a Tafel constant could not be measured, a typical value of $0.12 \mathrm{~V}$, for which the overpotential of the forward and reverse reactions are equal, was used [9]. This value is near the midpoint of experimental determinations of Tafel constants in many systems.

The polarization resistance, $R_{p}$, is related to the corrosion rate by the equation [9]

$$
R_{P}=\frac{B}{i_{\text {corr }}}
$$

where $i_{\text {corr }}$ is the corrosion current density at which the cathodic and anodic reaction rates are equal, and $B$ is related to the Tafel constants by:

$$
B=\frac{\beta_{a} \beta_{c}}{2.3\left(\beta_{a}+\beta_{c}\right)}
$$

From Equation 3, $i_{\text {corr }}$ can be calculated from the polarization resistance and Tafel constants and used in the equation

$$
r=\frac{k \cdot i_{\text {corr }} \cdot E W}{D}
$$

where $k$ is a conversion constant, $E W$ is the equivalent weight (by ASTM standard, EW is considered unitless, with the conversion constant used to account for units and convert 
to the appropriate length per time units), and $D$ is the density in $\mathrm{g} / \mathrm{cm}^{3}$ of the alloy. This will yield a general corrosion rate for the alloy/electrolyte system. The conversion constant, $k$, with a value of $3.27 \mu \mathrm{m} \cdot \mathrm{g} / y r \cdot \mu \mathrm{A} \cdot \mathrm{cm}$ was used to give a corrosion rate in units of $\mu \mathrm{m} / \mathrm{yr}$ [10]. In this way, corrosion rates were determined for the alloys. Figure 5 plots the average polarization resistance corrosion rates versus the average test solution $\mathrm{pH}$. All of the alloys had corrosion rates of less than $3 \mu \mathrm{m} / \mathrm{yr}$. There was not a significant trend of corrosion rate with Mo content, although Ni-20Cr, with no Mo, had the lowest instantaneous corrosion rates at all the $\mathrm{pH}$ values investigated.

\section{Passive Current Corrosion Rate:}

Corrosion rates were also determined from potentiostatic current measurements. The samples were held potentiostatically for 60,000 seconds at different voltages in both the active and passive potential regions. The near-steady-state current measured after holding the sample at a specific potential for a long period of time can be calculated by substituting the final current for $i_{\text {corr }}$ in equation (5). This calculation represents the passive corrosion rate of the alloy in an oxidizing environment where the corrosion potential is elevated. Figure 6 shows the final current corrosion rates of 3 alloys in $1 \mathrm{M}$ $\mathrm{NaCl}$ solutions (Ni-11Cr-13Mo was not tested). The corrosion rate for all of the alloys is low at all $\mathrm{pH}$ values, typically below $4 \mu \mathrm{m} / \mathrm{yr}$.

The average and standard deviation of the corrosion rate for the 4 alloys measured by both polarization resistance and potentiostatic final current density in all environments is $0.99 \pm 1.11 \mu \mathrm{m} / \mathrm{yr}$, which is consistently low. There were small variations between solutions tested, as seen in Figure 5. The low and high $\mathrm{pH}$ solutions had slightly higher corrosion rates for all alloys tested, while the $\mathrm{pH} 8$ solutions had the lowest corrosion rates. This can be attributed to the change in solubility of $\mathrm{Cr}_{2} \mathrm{O}_{3}$ with $\mathrm{pH}$. At high and low $\mathrm{pH}, \mathrm{Cr}_{2} \mathrm{O}_{3}$ is more soluble than at neutral $\mathrm{pH}$ 's [11]. However, the passive current corrosion rate was higher in the near neutral solution than the more extreme solutions (see Figure 6). This can be explained by kinetics of passive film formation. The more aggressive solutions formed a passive layer rapidly when the potential was raised slightly above the open circuit potential. Samples held in the $\mathrm{pH} 8$ solution do not reach a steady 
state within 60,000 seconds. Thus, the lack of aggressiveness of the $\mathrm{pH} 8$ solutions led to a slightly increased passive current.

\section{Discussion:}

The primary finding of this study is that chromium is responsible for the passive behavior and high breakdown potential whereas molybdenum is responsible for repassivation after breakdown occurs. This trend is illustrated by Figure 7, and can be seen in the data by examining the general behavior of the alloys in the different solutions represented in Figure 4. The passive film formed in the passive region of the alloys tested consisted predominately of chromium oxides. X-ray Photoelectron Spectroscopy and Auger data shows very little nickel and small amounts of molybdenum in the passive films. The results of these analyses will be discussed elsewhere [12]. The film composition analysis, as well as the passive behavior of the chromium containing alloys indicates the passive corrosion behavior is primarily controlled by the presence of chromium, which forms a $\mathrm{Cr}_{2} \mathrm{O}_{3}$ film, protecting the surface. The $\mathrm{Cr}_{2} \mathrm{O}_{3}$ film passivates the surface once complete coverage of the metal surface occurs. A threshold $\mathrm{Cr}$ concentration in the alloy of approximately 11\% [13] is required before complete passivation of the surface is seen. Above this threshold, a complete monolayer coverage of chromium oxide passivates the surface. Alloys Ni-11Cr-7Mo and Ni-11Cr-13Mo tested in this study have $\mathrm{Cr}$ concentrations of $11 \%$.

The theories that have been proposed to explain the role of Mo in the inhibition of localized corrosion relate to three main areas:

1) Passivation of the surface

2) Modification of the local solution

3) Modification of the alloy surface

In the first case, passivation of the surface occurs by the formation of a passive film when molybdenum precipitates on the surface as an oxide or intermetallic oxide within a pit, which protects the pit from further dissolution, retarding the growth of the pit [14-16]. The molybdenum inhibits corrosion by forming a molybdate $[6,17,18]$.

In the second case, modification of the local solution occurs by reducing the concentration of acid or aggressive constituents such as sulfur. There is some evidence 
that molybdenum decreases the passive corrosion rate of the alloy [19], thus decreasing the amount of dissolved metallic ions that can lead to hydrolysis and acidification. This in turn increases the time it takes to reach a critical solution to break down the passive film. In stainless steels it has been found that Mo can complex with sulfur, removing it from the surface, thus preventing pit formation, and there is some evidence for the interaction of $\mathrm{Mo}$ and $\mathrm{Cl}$, which can form a chemisorbed salt film protecting the surface and preventing the breakdown of the passive film due to the aggressive $\mathrm{Cl}^{-}$ion $[20,21]$.

In the third case, modification of the alloy surface occurs by preferential dissolution of non-Mo alloy components, leading to Mo enrichment of the metal surface. It has been suggested that this takes place by Mo enriching at kinks or step sites on the metal surface, slowing their dissolution, or by forming an enriched alloy at the surface of a stainless steel after the preferential dissolution of iron in stainless steels [4,5]. Preferential dissolution of one alloy component can also lead to a restructuring of the surface into an alloy with increased corrosion resistance properties [15,22]. All of these mechanisms may contribute collectively to the protection of an alloy, or they may be individually responsible for passivation depending on the solution and potential regimes.

While there is some trending of the breakdown potential with Mo content in the $\mathrm{pH} 8$ solution, there is very little variation in the $\mathrm{pH} 3$ and 11 solutions. This suggests that molybdenum has very little effect on the breakdown of the passive film, and thus localized pitting resistance is due to chromium. This agrees with Wanklyn [18], who, in a study of stainless steels 431, 316, and alloy $625 \mathrm{in} \mathrm{KCl}$ and $\mathrm{HCl}$ solutions, added Mo ${ }^{\mathrm{III}}$ in the form of $\mathrm{K}_{3} \mathrm{MoCl}_{6}$ and $\mathrm{Mo}{ }^{\mathrm{VI}}$ in the form of $\mathrm{Na}_{2} \mathrm{MoO}_{4}$ to his solutions. It was found that only $\mathrm{Mo}^{\mathrm{VI}}$ inhibited pitting, either by shifting the potential of the crevice or pit negatively, or by competing with the diffusion of the $\mathrm{Cl}^{-}$ion. In stainless steels, the pitting potential is well below the potential for the formation of $\mathrm{MoO}_{4}{ }^{2-}\left(\mathrm{Mo}^{\mathrm{VI}}\right)$. However, Lillard et al. [6] showed that for nickel based alloys, the pitting potential was such that this species could form during pit initiation, when the pitting solution was still relatively neutral. Once the pit formed, and began to acidify, the $\mathrm{pH}$ of the solution made $\mathrm{MoO}_{4}{ }^{2-}$ thermodynamically unstable, and it would form $\mathrm{MoO}_{2}$ by the reaction $\mathrm{MoO}_{4}{ }^{2-}+$ $4 \mathrm{H}^{+}+2 \mathrm{e}^{-} \rightarrow \mathrm{MoO}_{2}+\mathrm{H}_{2} \mathrm{O}$. As the alloy dissolved further, releasing more $\mathrm{Cr}$ ions into solution for hydrolysis, the $\mathrm{pH}$ would push the reaction to $\mathrm{MoO}_{2}+4 \mathrm{H}^{+}+\mathrm{e}^{-} \rightarrow \mathrm{Mo}^{3+}+$ 
$2 \mathrm{H}_{2} \mathrm{O}$. Thus, the Mo would inhibit corrosion by reducing the amount of acid in solution, but only temporarily until more hydrolysis occurred. Furthermore, $\mathrm{MoO}_{2}$ formed in the pit can serve as a physical barrier to pit propagation, and diffusion of species into and out of the pit [15]. Rebak et al. [23] have observed molybdenum oxide formation in crevices during crevice corrosion experiments on various nickel-chrome-molybdenum alloys. A specific driving potential must be applied to the alloy to maintain a dissolution rate such that the hydrolysis of chromium exceeds the inhibiting effect of Mo. This driving force would depend on the amount of Mo in the alloy. Alloy 22, with 13\% Mo repassivates as soon as the driving force is removed, and $\mathrm{Ni}-11 \mathrm{Cr}-7 \mathrm{Mo}$ with $7 \%$ Mo does not repassivate until near the open circuit potential. Ni-11Cr-13Mo, with 13\% Mo shows variation in its repassivation behavior (Fig. 1C, and 2C), suggesting that this is near the critical molybdenum concentration to inhibit pitting.

This is reinforced by the behavior of the alloys at the basic $\mathrm{pH}$ solutions near $\mathrm{pH}$ 11. All of the alloys containing Mo repassivate very close to their breakdown potentials, and all of the alloys breakdown at about $500 \mathrm{mV}$. Since the solution is basic, the $\mathrm{MoO}_{4}{ }^{2-}$ species is stable, and prevents the formation of pits. Once breakdown occurs, it is very difficult for the pit to sustain an acidic solution, both due to the molybdate, and the diffusion of hydroxil groups. In acidic solutions a higher Mo content is necessary to repassivate an active pit (compare Fig. 1B and 3B). In the $\mathrm{pH} 11$ solution, the bulk solution (by diffusion) may aid the neutralization of an active pit, so Mo may be less important, as demonstrated in Figure 4C.

The pit inhibiting behavior of Mo has been attributed to a reduction of the passive current of the alloy, thus reducing the rate of acidification of the pit environment. In a study comparing Alloy 625 to Alloy 276, Lillard [6] found that Alloy 276 had a lower passive current density, and was less susceptible to pitting. In a study on Alloy 276 and Alloy 22, Lloyd et al. [24] found that Alloy 22 had a lower passive current density, and was less susceptible to pitting as well. This matches the theory regarding the passive current density; although, when comparing the components of the alloys, Alloy 276 has more Mo than both Alloy 22 and 625, and Alloy 625 has as much Cr as Alloy 22 and 6\% more than Alloy 276. When comparing the alloys in this study, the $\mathrm{Cr}$ and Mo contents were varied over a wide range, yet the passive current corrosion rates, and the cyclic 
polarization scans reveal that in the solutions tested, in salt solutions with pH's from 3 to 11, the passive current densities varied very little. This suggests that the addition of chromium beyond a critical threshold does not significantly improve the corrosion resistance as measured by corrosion rates or breakdown potential. However, increasing the Mo content of the alloys significantly improves the repassivation behavior. Continued improvement is seen as the Mo content increases, contrasting with increasing additions of $\mathrm{Cr}$, which has little effect beyond a specific threshold value of approximately $11 \%$. Once pitting occurs, the high breakdown potential of nickel alloys allows the formation of an inhibiting molybdate, which slows the propagation of the pit, and aids in repassivation once the overpotential is decreased.

\section{Conclusions:}

The passive corrosion behavior of $\mathrm{Ni}-\mathrm{Cr}-\mathrm{Mo}$ alloys in $\mathrm{NaCl}$ solutions with $\mathrm{pH}$ values in the range of $3-11$ is controlled by the $\mathrm{Cr}$ content of the alloy. The main effect of adding Mo to the alloy is an ennobling of the repassivation behavior. The repassivation potential scales with the amount of Mo added to the alloy for the solutions examined in this study. This behavior can be attributed to the formation of a molybdenum oxide during pitting, or the enrichment of Mo metal at the alloy surface. The molybdenum oxide film can block the further dissolution of the pit, as well as modify the local solution environment by consuming $\mathrm{H}^{+}$ions, thus decreasing the acidity of the pit.

This work was performed under the auspices of the U.S. Department of Energy by University of California, Lawrence Livermore National Laboratory under Contract W7405-Eng-48. 
1 W. Z. Friend, Corrosion of Nickel and Nickel-base Alloys (Wiley-Interscience, New York, 1980).

2 F. G. Hodge, and B.E. Wilde, Corrosion 26, 146 (1970).

3 D. L. Piron, E.P. Koutsoukos, and K. Nobe, Corrosion 25, 151 (1969).

$4 \quad$ R. C. Newman, Corrosion Science 25, 331-339 (1985).

$5 \quad$ R. C. Newman, Corrosion Science 25, 341-350 (1985).

6 R. S. Lillard, M. P. Jurinski, and J. R. Scully, Corrosion 50, 251-265 (1994).

7 ASTM International, Annual Book of Standards Vol. 03.02 (G59, G61, G102), West Conshohocken, PA, ASTM 2004.

8 M. G. Fontana and N.D. Greene, Corrosion Engineering, McGraw-Hill, New York, 1978.

9 D. A. Jones, Principles and Prevention of Corrosion, 2nd ed. (Prentice Hall, New Jersey, 1996).

The conversion constant, $k$, for a corrosion rate, $r$, in units of $\mu \mathrm{m} / \mathrm{yr}$ is derived below.

The rate, $r=\frac{i_{c o r r} \cdot E W}{D}$ expressed in terms of units, using the true units for $\boldsymbol{E W}\left(\frac{\mathrm{g}}{\mathrm{mol} \cdot e^{-}}\right)$is $\frac{\mu m}{y r}=\frac{\frac{\mu A}{\mathrm{~cm}^{2}} \cdot \frac{\mathrm{g}}{\mathrm{mol} \cdot e^{-}}}{\frac{\mathrm{g}}{\mathrm{cm}^{3}}}=\frac{\mu A \cdot \mathrm{cm}}{\mathrm{mol} \cdot \mathrm{e}^{-}}$. By rewriting the current in terms of coulombs, $\boldsymbol{C}$, this becomes $\frac{\mu m}{y r}=\frac{\mu \mathrm{C} \cdot \mathrm{cm}}{\mathrm{sec} \cdot \mathrm{mol} \cdot \mathrm{e}^{-}}$. Expressing $\boldsymbol{C}$ in $\boldsymbol{e}^{-}$per $\boldsymbol{C}$ and using Avogadro's number this becomes $\frac{\mu m}{y r}=\frac{10^{-6} \cdot C \cdot 6.25 \times 10^{18} e^{-} / \mathrm{C} \cdot \mathrm{cm}}{\mathrm{sec} \cdot 6.02 \times 10^{23} \cdot e^{-}}=3.27 \frac{\mu m}{y r}$. By ASTM standards, $E W$ is treated as unitless, with the constant $k$ accounting for units. Thus, $k=3.27 \frac{\mu m \cdot g}{y r \cdot \mu A \cdot c m}$.

11 Marcel Pourbaix, Atlas of Electrochemical Equilibria in Aqueous Solutions, NACE int., Houston TX, 1974. J.R. Hayes, J.J. Gray, A. Szmodis C. Orme, (To Be Submitted). A. John Sedriks, Corrosion of Stainless Steels, John Wiley and Sons, inc., New York, New York, 1996.

R. Qvarfort, Corrosion Science 40, 215-223 (1998). 1913-1922 (1993). 
21 J. M. Bastidas, C. L. Torres, E. Cano, and J. L. Polo, Corrosion Science 44, 625-633 (2002).

22 I. Olefjord and B-O. Elfstrom, Corrosion 38, 46-52 (1982).

23 R.B. Rebak, N.E. Koon, J.P. Cotner, and P. Crook, Passivity and Localized Corrosion, The Electrochemical Society Proceedings Volume 99-27, 473 (1999).

24 A. C. Lloyd, D. W. Shoesmith, N. S. McIntyre, and J. J. Noel, J. Electrochem. Soc. 150, B120-B130 (2003). 
Figure 1: Potentiodynamic polarization curves of the 4 alloys in $1 \mathrm{M} \mathrm{NaCl}$ at $\mathrm{pH} 3.09 \pm 0.37$ and 90 ${ }^{\circ} \mathrm{C}$. The curves are for Ni-20Cr (A), Ni-11Cr-7Mo (B), Ni-11Cr-13Mo (C), and Alloy 22 with $22 \% \mathrm{Cr}$ and $13 \%$ Mo (D). The alloy in (C) displayed both active behavior, shown as a dashed line, and passive behavior, shown as a solid line during replicate testing.

Figure 2: Potentiodynamic polarization curves of the 4 alloys in $1 \mathrm{M} \mathrm{NaCl}$ at $\mathrm{pH} 7.78 \pm 0.22$ and 90 ${ }^{\circ} \mathrm{C}$. The curves are for Ni-20Cr (A), Ni-11Cr-7Mo (B), Ni-11Cr-13Mo (C), and Alloy 22 with $22 \% \mathrm{Cr}$ and $13 \%$ Mo (D). The alloy in (C) displayed both active behavior, shown as a dashed line, and passive behavior, shown as a solid line during replicate testing.

Figure 3: Potentiodynamic polarization curves of the 4 alloys in $1 \mathrm{M} \mathrm{NaCl}$ at $\mathrm{pH} 10.96 \pm 0.05$ and 90 ${ }^{\circ} \mathrm{C}$. The curves are for Ni-20Cr (A), Ni-11Cr-7Mo (B), Ni-11Cr-13Mo (C), and Alloy 22 with $22 \% \mathrm{Cr}$ and $13 \%$ Mo (D).

Figure 4: Comparison of the breakdown and repassivation potentials of the 4 alloys in $1 \mathrm{M} \mathrm{NaCl}$ solutions at $\mathrm{pH} 3.09 \pm 0.37$ (A), $\mathrm{pH} 7.78 \pm 0.22$ (B), and $\mathrm{pH} 10.96 \pm 0.05$ (C) held at $90{ }^{\circ} \mathrm{C}$. The Mo content of the alloys increases to the right. Also plotted in the figure are the measured potential at which oxygen evolves on a platinum working electrode (dashed line), and the calculated oxygen redox potential under the test conditions, assuming an oxygen partial pressure of $10^{-6} \mathrm{~atm}$. (dotted line). The vertical tie lines indicate the level of hysteresis between breakdown and repassivation as represented in Figures 1-3. The data in this figure were derived from two potentiodynamic tests for each alloy/solution combination. Transpassive breakdown of the alloys resulted in pitting, crevicing, or general dissolution of the samples for pH's 3 and 8 . At $\mathrm{pH}$ 11, with the exception of Ni-Cr20, transpassive breakdown is due solely to oxygen evolution.

Figure 5: The average polarization resistance corrosion rates of the 4 alloys determined from polarization resistance measurements after 24 hours in $90{ }^{\circ} \mathrm{C} 1 \mathrm{M} \mathrm{NaCl}$ solutions of various $\mathrm{pH}$ values. The error bars represent the standard deviation of corrosion rate and solution $\mathrm{pH}$ for the specimens tested.

Figure 6: Corrosion rates in $1 \mathrm{M} \mathrm{NaCl}$ solutions of various $\mathrm{pH}$ 's held at $90^{\circ} \mathrm{C}$ calculated from the current obtained after holding a sample potentiostatically for 60,000 seconds. Three alloys were tested at various potentials within the active and passive range at the potentials indicated on the

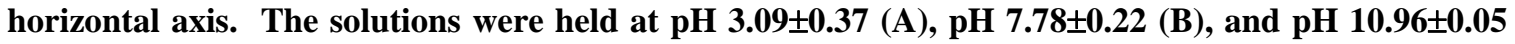
(C).

Figure 7: Illustration of the behavior of molybdenum containing $\mathrm{Ni} / \mathrm{Cr}$ alloys. A nickel alloy containing at least $11 \% \mathrm{Cr}$ will have a fairly consistent breakdown potential in a salt solutions with a variety of pH's (from 3 to 11), as represented by the band at the top. The repassivation of the alloy, however, is strongly dependent on the Mo content. As Mo concentration increases, the repassivation potential increases. 
Table 1: The weight percent alloy compositions of the alloys tested, with their associated densities (D) and equivalent weights (EW)* used in the calculation of corrosion rates.

\begin{tabular}{c|ccccccc}
\hline Alloy & $\mathrm{Ni}(\mathrm{w} \%)$ & $\mathrm{Cr}(\mathrm{w} \%)$ & $\mathrm{Mo}(\mathrm{w} \%)$ & $\mathrm{W}(\mathrm{w} \%)$ & $\mathrm{Fe}(\mathrm{w} \%)$ & $\mathrm{D}\left(\mathrm{g} / \mathrm{cm}^{3}\right)$ & $\mathrm{EW}$ \\
\hline \hline Ni-20Cr & 80 & 20 & 0 & 0 & 0 & 8.57 & 25.77 \\
Ni-11Cr-7Mo & 82 & 11 & 7 & 0 & 0 & 8.75 & 25.86 \\
Ni-11Cr-13 Mo & 76 & 11 & 13 & 0 & 0 & 8.82 & 24.77 \\
Alloy 22 & 59 & 22 & 13 & 3 & 3 & 8.69 & 23.28 \\
\hline
\end{tabular}

*The equivalent weight is taken as unitless according to ASTM standard G102. A conversion constant is used to account for units when calculating corrosion rates from this quantity [10]. 
Table 2: The alloys were tested in three $\mathrm{NaCl}$ based solutions with various $\mathrm{pH}$ values. The $\mathrm{NaCl}$ solutions are referred to by their approximate $\mathrm{pH}$.

\begin{tabular}{l|ccc}
\hline \multicolumn{4}{c}{ Solution Concentrations in Molal } \\
\hline & $\mathrm{pH} 3 \mathrm{NaCl}$ & $\mathrm{pH} 8 \mathrm{NaCl}$ & $\mathrm{pH} 11 \mathrm{NaCl}$ \\
\hline \hline Borate & -- & 0.1 & -- \\
Hydrochloric Acid & 0.01 & -- & -- \\
KH-Phthalate & 0.05 & -- & -- \\
Sodium Chloride & 1.05 & 1.05 & 1.00 \\
Sodium Hydroxide & -- & 0.02 & 0.15 \\
\hline
\end{tabular}


Table 3: Anodic Tafel constants $\left(\beta_{a}\right)$ and cathodic Tafel constants $\left(\beta_{c}\right)$ of the 4 alloys in the various $1 \mathrm{M} \mathrm{NaCl}$ solutions, calculated from potentiodynamic polarization curves. When the calculation could not be made due to the shape of the polarization curve, a standard value of $0.12 \mathrm{~V}$ was used.

\begin{tabular}{c|ccc||ccc}
\hline & \multicolumn{3}{|c||}{$\beta_{\mathrm{a}}(\mathrm{V})$} & \multicolumn{3}{c}{$\beta_{\mathrm{c}}(\mathrm{V})$} \\
\cline { 2 - 7 } Alloy & $\mathrm{pH} \mathrm{2.8}$ & $\mathrm{pH} \mathrm{7.5}$ & $\mathrm{pH} \mathrm{11}$ & $\mathrm{pH} \mathrm{2.8}$ & $\mathrm{pH} \mathrm{7.5}$ & $\mathrm{pH} \mathrm{11}$ \\
\hline \hline Ni-20Cr & 0.13 & 0.18 & 0.26 & 0.11 & 0.17 & 0.19 \\
Ni-11Cr-7Mo & 0.12 & 0.15 & 0.31 & 0.12 & 0.08 & 0.17 \\
Ni-11Cr-13 Mo & 0.12 & 0.44 & 0.43 & 0.12 & 0.27 & 0.33 \\
Alloy 22 & 0.29 & 0.17 & 0.28 & 0.25 & 0.14 & 0.27 \\
\hline
\end{tabular}


Figure 1: Potentiodynamic polarization curves of the 4 alloys in $1 \mathrm{M} \mathrm{NaCl}$ at $\mathrm{pH} 3.09 \pm 0.37$ and 90 ${ }^{\circ} \mathrm{C}$. The curves are for Ni-20Cr (A), Ni-11Cr-7Mo (B), Ni-11Cr-13Mo (C), and Alloy 22 with $22 \% \mathrm{Cr}$ and $13 \%$ Mo (D). The alloy in (C) displayed both active behavior, shown as a dashed line, and passive behavior, shown as a solid line during replicate testing.

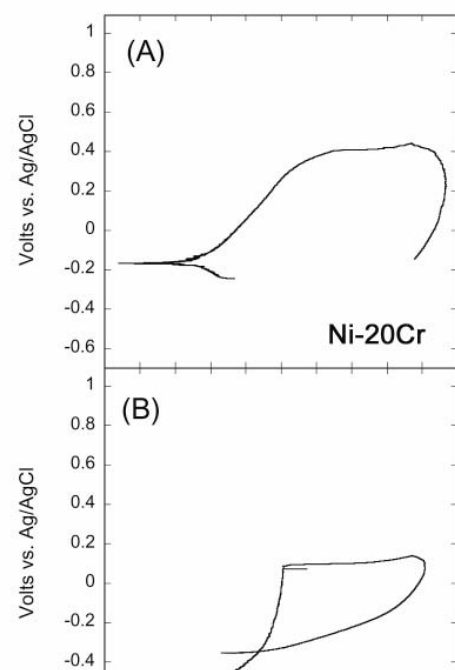

\section{Please use attached PDF file for graphic.}

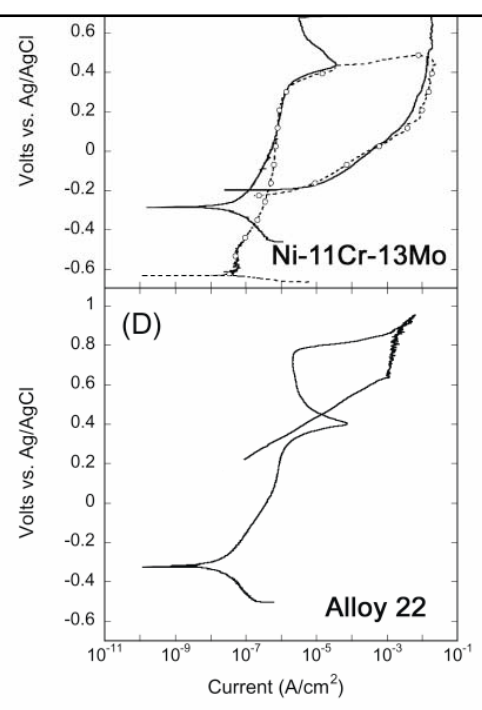


Figure 2: Potentiodynamic polarization curves of the 4 alloys in $1 \mathrm{M} \mathrm{NaCl}$ at pH $7.78 \pm 0.22$ and 90 ${ }^{\circ} \mathrm{C}$. The curves are for Ni-20Cr (A), Ni-11Cr-7Mo (B), Ni-11Cr-13Mo (C), and Alloy 22 with $22 \% \mathrm{Cr}$ and $13 \%$ Mo (D). The alloy in (C) displayed both active behavior, shown as a dashed line, and passive behavior, shown as a solid line during replicate testing.

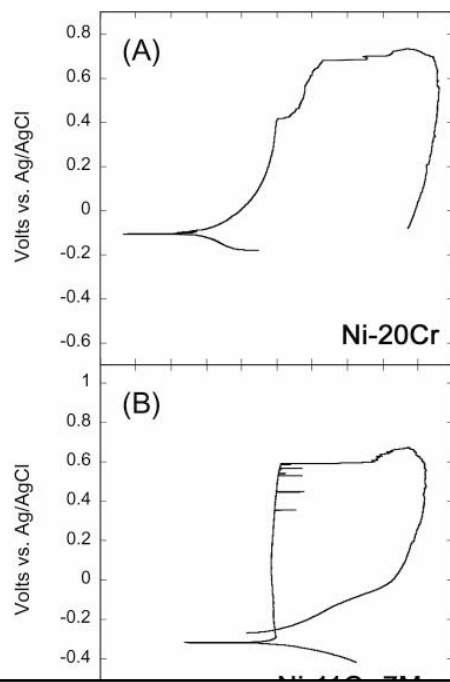

Please use attached PDF file for graphic.

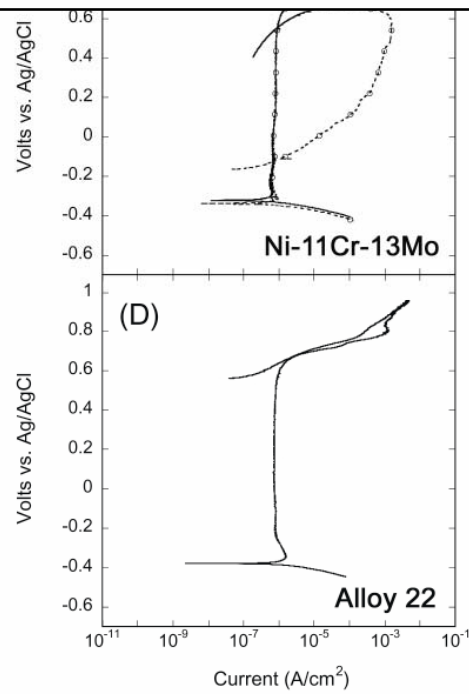


Figure 3: Potentiodynamic polarization curves of the 4 alloys in $1 \mathrm{M} \mathrm{NaCl}$ at $\mathrm{pH} 10.96 \pm 0.05$ and 90 ${ }^{\circ} \mathrm{C}$. The curves are for Ni-20Cr (A), Ni-11Cr-7Mo (B), Ni-11Cr-13Mo (C), and Alloy 22 with $22 \% \mathrm{Cr}$ and $13 \%$ Mo (D).

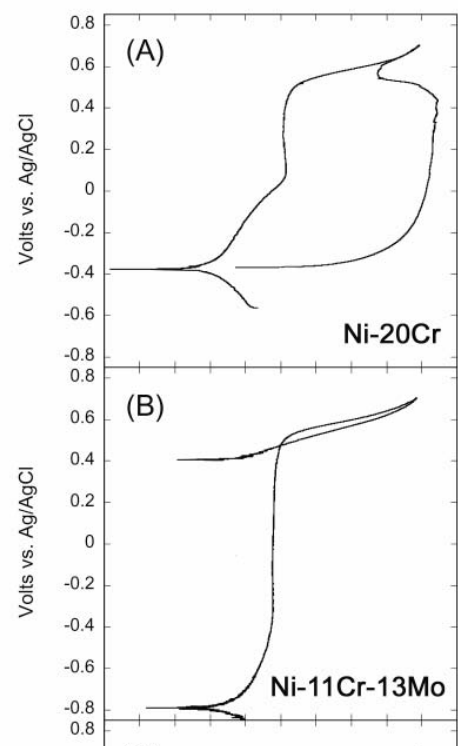

Please use attached PDF file for graphic.

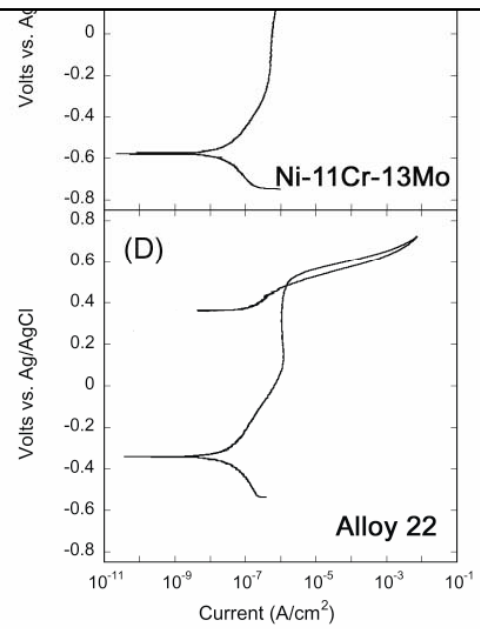


Figure 4: Comparison of the breakdown and repassivation potentials of the 4 alloys in $1 \mathrm{M} \mathrm{NaCl}$ solutions at $\mathrm{pH} 3.09 \pm 0.37$ (A), $\mathrm{pH} 7.78 \pm 0.22$ (B), and $\mathrm{pH} 10.96 \pm 0.05$ (C) held at $90{ }^{\circ} \mathrm{C}$. The Mo content of the alloys increases to the right. Also plotted in the figure are the measured potential at which oxygen evolves on a platinum working electrode (dashed line), and the calculated oxygen redox potential under the test conditions, assuming an oxygen partial pressure of $10^{-6} \mathrm{~atm}$. (dotted line). The vertical tie lines indicate the level of hysteresis between breakdown and repassivation as represented in Figures 1-3. The data in this figure were derived from two potentiodynamic tests for each alloy/solution combination. Transpassive breakdown of the alloys resulted in pitting, crevicing, or general dissolution of the samples for pH's 3 and 8 . At $\mathrm{pH}$ 11, with the exception of Ni-Cr20, transpassive breakdown is due solely to oxygen evolution.

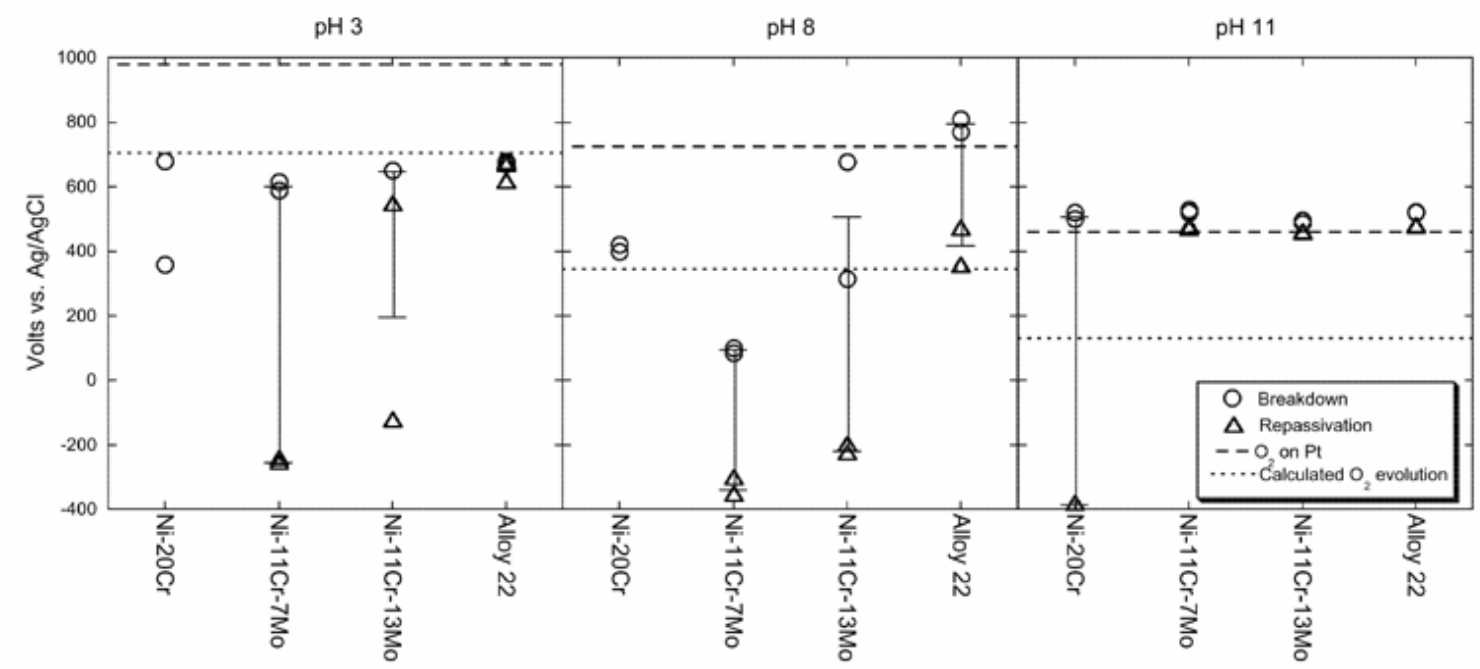

Please use attached PDF file for graphic. 
Figure 5: The average polarization resistance corrosion rates of the 4 alloys determined from polarization resistance measurements after 24 hours in $90{ }^{\circ} \mathrm{C} 1 \mathrm{M} \mathrm{NaCl}$ solutions of various $\mathrm{pH}$ values. The error bars represent the standard deviation of corrosion rate and solution $\mathrm{pH}$ for the specimens tested.

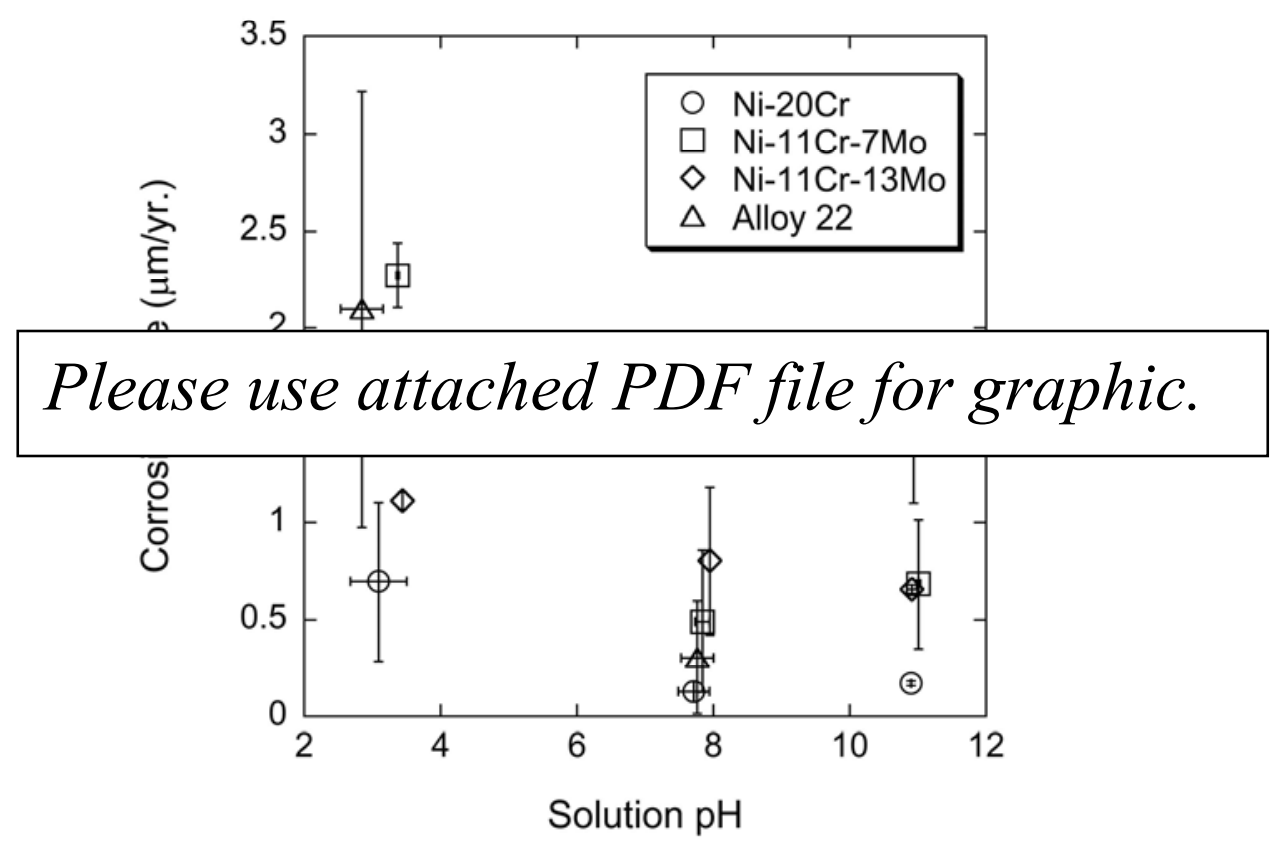


Figure 6: Corrosion rates in $1 \mathrm{M} \mathrm{NaCl}$ solutions of various $\mathrm{pH}$ 's held at $90^{\circ} \mathrm{C}$ calculated from the current obtained after holding a sample potentiostatically for 60,000 seconds. Three alloys were tested at various potentials within the active and passive range at the potentials indicated on the horizontal axis. The solutions were held at $\mathrm{pH} 3.09 \pm 0.37$ (A), $\mathrm{pH} 7.78 \pm 0.22$ (B), and pH 10.96 \pm 0.05 (C).

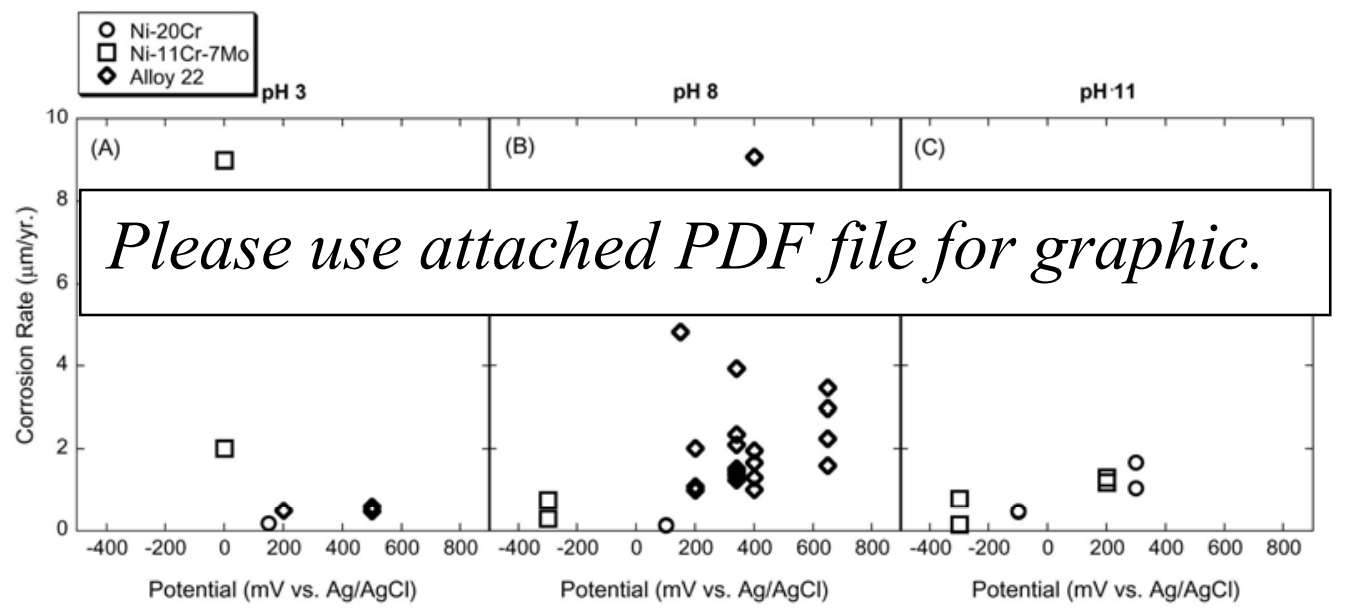


Figure 7: Illustration of the behavior of molybdenum containing Ni/Cr alloys. A nickel alloy containing at least $11 \% \mathrm{Cr}$ will have a fairly consistent breakdown potential in a salt solutions with a variety of pH's (from 3 to 11), as represented by the band at the top. The repassivation of the alloy, however, is strongly dependent on the Mo content. As Mo concentration increases, the repassivation potential increases.

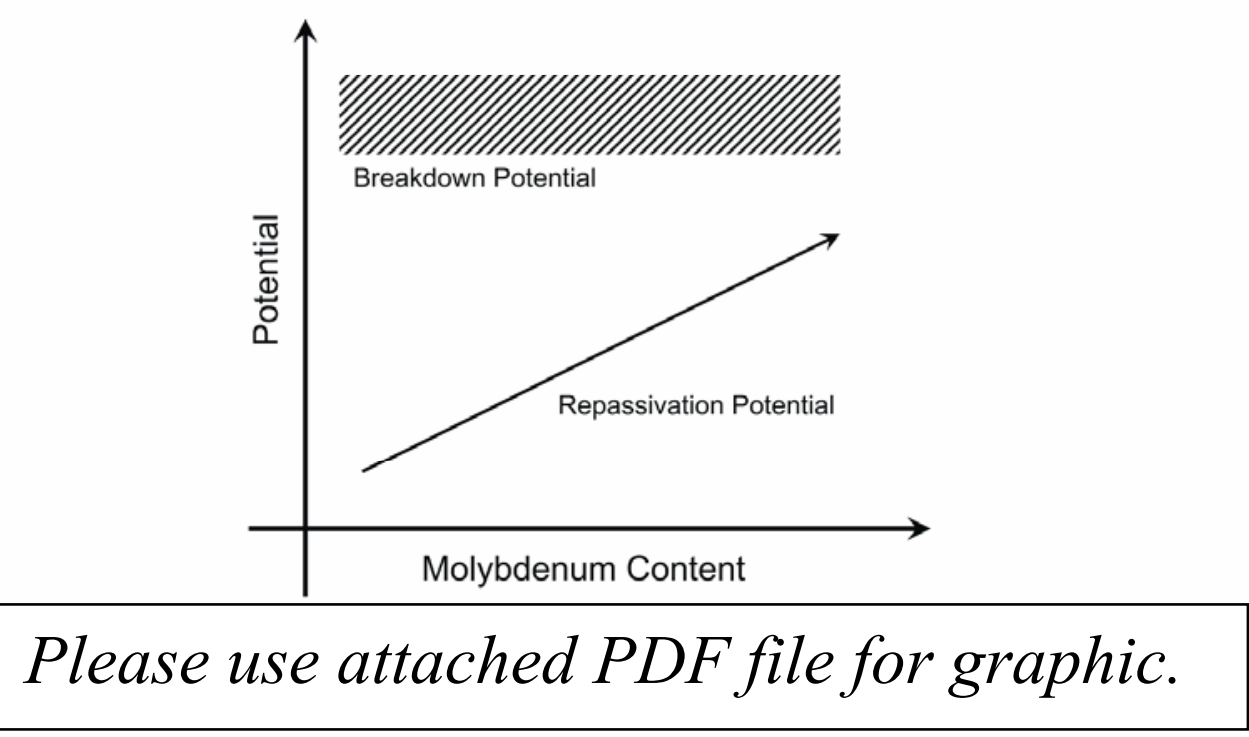

